Tjalling C. Koopmans Research Institute Tplligh Aoopman

Discussion Paper Series nr: 06-10

\title{
Why Suggest Non-Binding Retail Prices?
}

Clemens Puppe and Stephanie Rosenkranz 


\section{Tjalling C. Koopmans Research Institute Utrecht School of Economics \\ Utrecht University}

Vredenburg 138

3511 BG Utrecht

The Netherlands

telephone +31302539800

fax $\quad+31302537373$

website www.koopmansinstitute.uu.nl

The Tjalling C. Koopmans Institute is the research institute and research school of Utrecht School of Economics.

It was founded in 2003, and named after Professor Tjalling C. Koopmans, Dutch-born Nobel Prize laureate in economics of 1975.

In the discussion papers series the Koopmans Institute publishes results of ongoing research for early dissemination of research results, and to enhance discussion with colleagues.

Please send any comments and suggestions on the Koopmans institute, or this series to M.deSwart-Gijsbers@econ.uu.nl

ontwerp voorblad: WRIK Utrecht

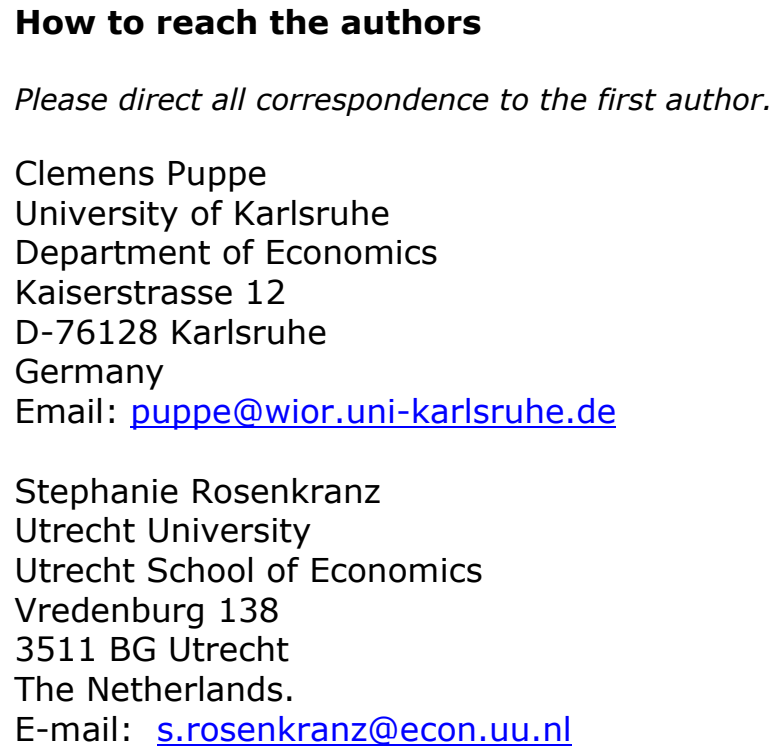


Utrecht School of Economics

Tjalling C. Koopmans Research Institute

Discussion Paper Series 06-10

\title{
Why Suggest Non-Binding Retail Prices?
}

\author{
Clemens Puppe \\ Stephanie Rosenkranz ${ }^{\mathrm{b}}$ \\ ${ }^{a}$ University of Karlsruhe \\ Department of Economics \\ bUtrecht School of Economics \\ Utrecht University
}

May 2006

\begin{abstract}
We provide a simple behavioral explanation of why manufacturers frequently announce non-binding suggested retail prices for their products. Our model is based on the assumption that once the actual price for a product exceeds its suggested retail price, the marginal propensity to consume suddenly jumps downward. This property of individual demand corresponds to Kahneman and Tversky's concept of loss aversion. We show that it may induce a monopolistic retailer to set the price equal to the suggested retail price in equilibrium, although the latter price is nonbinding. This, in turn, leads to a shift of profits from the retailer to the manufacturer.
\end{abstract}

Keywords: manufacturer's suggested retail price, reference dependence, loss aversion

JEL classification: D4, D10, L1, L2

Acknowledgements

The paper is based on an unpublished working paper by the second author, Stephanie Rosenkranz (2003). Acknowledgements to be added. 


\section{Introduction}

Many examples indicate that manufacturers frequently publicly advertise with suggested retail prices even though they do not have any direct influence on the retailer's obedience. Car manufacturers, as Mitsubishi and Hyundai, software manufacturers as Microsoft, manufacturers of Swiss watches as Swatch or Jaeger leCoutre, as well as the manufacturers of cosmetics as Vichy or Claire Fisher or of chocolate brands, as Lindt, advertise in magazines and other media with a manufacturer's suggested retail price.

Given that this pricing policy is rather common it is surprising that there is no comprehensive economic explanation for the phenomenon so far. A closer look at the different legal approaches to price maintenance pursued in various countries underpins the impression that the underlying economic reasoning is based on loose and unconnected arguments. While retail price maintenance as a direct vertical restraint is prohibited as a per 
se antitrust violation by antitrust laws in many countries, the permission of suggested (i.e. non-binding) retail prices is supported with a smorgasbord of arguments.

In Canada, for example, suggested retail prices are not prohibited provided that it is made clear to the retailer that he is "under no obligation to accept the suggestion and would not suffer in his business relations (...) if he failed to accept the suggestion" and provided that "the price is so expressed as to make it clear to any person to whose attention the advertisement comes that the product may be sold at a lower price" (s61(3) and (4) of the Competition Act). In the US, the "Colgate doctrine" establishes the right of a manufacturer to condition a transaction with a retailer on the retailer's pricing activities and to impart its views on resale prices by providing a suggested retail price. He can furthermore induce retailers to use its suggested prices provided the manufacturer does so unilaterally and any compliance by the retailer to follow the suggestion is the result of its independent decision. In other words, a violation of antitrust law will not occur if no expressed or tacit "agreement" exists between the manufacturer and its complying retailers. In Germany, under the "Act against Restraints of Competition" (ARC) price recommendations are illegal in principle; they are only permitted if certain conditions are satisfied. Section 38 (1) No. 11 of the ARC says that suggested retail prices are "allowed for branded products if it is made clear that the price is suggested and that it is neither a price ceiling nor a minimum price, and that it corresponds to the expected price of a majority of customers." It may not be too high as to make a customer believe that the majority expects a significantly higher price than the effective retail price.

In fact, advertised suggested retail prices - on the product's package or a pricing tab, on brochures or even in an advertisement campaign often are a manufacturer's only possibility to try to influence the retail price when fixed price policies are illegal, or when the good is not sold on consignment. ${ }^{1}$

But why do manufacturers use this pricing strategy and how should the suggested retail price be set such that a retailer in fact accepts this price? Economic theory makes no clear distinction between suggested prices and retail price maintenance. The fact that retailers accept (suggested) vertical price fixing is explained either by collusive arguments or by assuming

\footnotetext{
${ }^{1}$ The latter is one exception of the per se illegality of resale price maintenance in the US under the General Electric doctrine.
} 
that the manufacturer has other possibilities to pressure retailers. ${ }^{2}$ The retailer cartel hypothesis is based on the assumption that the fixed suggested retail price serves as a coordination device for retailers and as an entry barrier against low-price, large volume outlets. ${ }^{3}$ The conditions for this hypothesis are the following: The retailers invested substantial assets in traditional low-volume outlets and entry of a discount chain store threatens the quasi rents earned by these outlets. The cartel must involve a number of retailers for substitute products with only one manufacturer and their common interest is to maximize joint profits irrespective of how profits are divided among them. If the cartelization is successful, entry may be blocked or at least delayed. The problem with this hypothesis is that it only is valid if the manufacturer agrees to foreclose the discount sector. Once the potential market share of this sector is growing, the manufacturer's gain from the cartel at the suggested retail price would be overcompensated by the cost of foreclosing the discount sector even if the traditional retailers had prevented cheating. ${ }^{4}$ Alternatively, the cartel hypothesis can be based on arguments from the agency literature which suggests that the manufacturer acts as a common marketing agency for the retailers and thereby facilitates collusion. ${ }^{5}$ More recently, Jullien and Rey (2000) have formalized the conventional wisdom according to which vertical restrictions on retail prices help upstream firms to collude. In their setting, retail price maintenance facilitates the detection of deviations by eliminating flexibility for the retail price to reflect local shocks on demand and costs.

A second explanation for fixed retail prices is grounded in the idea that a monopolistic manufacturer can effectively threaten his retailers to quit or to alter the business relation in case they do not follow the recommendation even if this behavior is illegal, because detection is rather difficult. This argument is based on the assumption that no retailer has enough market power as e.g. a large discounter may have.

In this paper, a different line of argument is proposed to explain the prevalence of suggested retail prices and the observation that retailers in

\footnotetext{
${ }^{2}$ See Bernheim and Whinston (1985) and Matthewson and Winter (1998).

${ }^{3}$ On this, see in particular Matthewson and Winter (1998).

${ }^{4}$ On the French book market, recommended prices (which were met by the retailers) were common until FNAC and Leclerc entered the market as large discount retailers. Thereafter a severe price war started which finally in 1981 induced a change in law, and retail price maintenance was allowed for printed products. See OCDE/GD(97)229 (1997).

${ }^{5}$ See Bernheim and Whinston (1985) for this line of argument.
} 
fact often price the products according to the non-binding recommendation. The argument is based on the hypothesis that a suggested retail price serves as a "reference point" and thus manipulates consumers' willingness to pay. Indeed, a number of psychological experiments point at the important role of reference points in individual choice. "The location of a reference point affects the coding of outcomes as gains and losses. This coding, in turn, affects preferences because of characteristic differences in the evaluation of positive and negative outcomes." ${ }^{6}$ Kahneman and Tversky $(1979,1984)$ emphasized in Prospect Theory that the value function is not only reference dependent but also loss averse and therefore steeper in the domain of losses than in the domain of gains. The concept used in this analysis will be in line with the concepts of reference dependence and loss aversion in the context of riskless choice which has been formalized by Tversky and Kahneman (1991) and Kahneman, Knetsch and Thaler (1991). We assume that in response to the suggested retail price consumers' willingness to pay is decreased if the retail price is above the suggested retail price.

For simplicity and clarity of exposition, we restrict the analysis to the case of a single monopolistic manufacturer and a single monopolistic retailer. In this respect the analysis is only a starting point, suggesting that most results from the literature on vertical strategic interactions are probably adjustable to the analyzed demand features. On the other hand, since collusion is not an issue in our set-up, the present analysis emphasizes the specific behavioral character of our explanation which differs fundamentally from the arguments put forward in the literature.

Our main findings are that the manufacturer always benefits from suggesting a retail price. If consumers' loss aversion is sufficiently strong (consumers' disappointment is sufficiently large), the manufacturer can and will force the retailer to choose the suggested retail price (or a higher price) in equilibrium and profits are shifted from the retailer to the manufacturer. When loss aversion becomes very strong, the manufacturer will suggest a price close to the monopoly price in equilibrium and the retailer has no other possibility than to buy and to sell the product at this price. In the limit, the retailer thus makes zero profit in equilibrium while the manufacturer realizes the monopoly profit on the market.

\footnotetext{
${ }^{6}$ See Kahneman (1992), p.297.
} 


\section{The Reference Model without Suggested Retail Prices}

A manufacturer produces a good at constant unit costs $c>0$ and sells it at price $p_{w}$ to a retailer. The retailer, in turn, sells it at the retail price $p_{r}$ facing a downward sloping market demand $\hat{D}\left(p_{r}\right)$. The (subgame perfect) equilibrium of this simple set-up is well-known and characterized by a double markup, as follows. For any given $p_{w}$, the retailer solves

$$
\max _{p_{r}}\left(p_{r}-p_{w}\right) \cdot \hat{D}\left(p_{r}\right) .
$$

Thus, the optimal price $p_{r}^{m}$ satisfies

$$
p_{r}^{m}\left[1+\frac{1}{\hat{\varepsilon}\left(p_{r}^{m}\right)}\right]=p_{w},
$$

where $\hat{\varepsilon}(\cdot)$ is the price elasticity of demand. For the solution $p_{r}^{m}\left(p_{w}\right)$ in $(2)$ to be well-defined we need to assume that demand is sufficiently elastic in the relevant range. This will follow from our general assumptions on the demand function stated below.

Next consider the manufacturer's problem. By backwards induction, the manufacturer solves

$$
\max _{p_{w}}\left(p_{w}-c\right) \cdot \hat{D}\left(p_{r}^{m}\left(p_{w}\right)\right) .
$$

The solution $p_{w}^{0}$ satisfies

$$
p_{w}^{0}\left[1+\frac{1}{\hat{\varepsilon}\left(p_{r}^{m}\left(p_{w}^{0}\right)\right)}\right]=c .
$$

Evidently, by (2) and (3), the market is characterized by a double price markup, i.e. the two firms share the surplus but total surplus is in general less than the monopoly profit. ${ }^{7}$

Note that in the absence of a retailer, on the other hand, the manufacturer could sell the product directly to consumers, setting the monopoly price $p^{m}:=p_{r}^{m}(c)$ and thereby realizing the monopoly profit $\left(p^{m}-c\right)$. $\hat{D}\left(p^{m}\right)$.

\footnotetext{
${ }^{7}$ Spengler (1950) was the first to describe this finding as double marginalization.
} 


\section{Equilibrium with Suggested Retail Prices}

Suppose now that the manufacturer has the additional strategic possibility to announce a non-binding "suggested" retail price $p_{s}$. Clearly, such nonbinding price announcement would have no effect on the equilibrium if it would not influence the retailer's profits. Here, we assume that the announcement of $p_{s}$ influences demand in a specific way, as follows.

\subsection{The Structure of the Demand Function}

By $D\left(p_{r}, p_{s}\right)$ we denote the demand function that now depends on the retail price $p_{r}$ (set by the retailer, as before) and on the suggested retail price $p_{s}$ (set by the manufacturer). Our basic assumption is that $D$ has a "kink" at $p_{r}=p_{s}$, i.e. that the marginal propensity to consume suddenly jumps downward once the actual retail price hits the publicly announced suggested retail price.

In order to be able to compare the results with suggested retail price with those that obtain in the model without it, we will assume more specifically that the demand $D\left(p_{r}, p_{s}\right)$ is derived from an underlying demand function $\hat{D}\left(p_{r}\right)$ as follows. For all fixed $p_{s}>0$,

$$
D\left(p_{r}, p_{s}\right)=\hat{D}\left(p_{r}\right) \text { if } p_{r} \leq p_{s}
$$

Intuitively, this condition says that the suggested retail price $p_{s}$ does not influence the demand when the actual retail price $p_{r}$ is below $p_{s}$. If, on the other hand, the retail price exceeds the suggested retail price, demand is smaller than it would be without suggested retail price, i.e. for all fixed $p_{s}$

$$
D\left(p_{r}, p_{s}\right)<\hat{D}\left(p_{r}\right) \text { if } p_{r}>p_{s}
$$

The behavioral assumption behind (4) and (5) is that consumers take the suggested retail price as a benchmark, viewing consumption at a higher price as a "loss." Thus, condition (5) can be interpreted as describing loss aversion in the sense of Tversky and Kahneman (1991). Their theory also suggests that the negative incremental utility due to losses is larger than the positive incremental utility resulting from corresponding gains. This implies that the utility functions incorporating loss aversion have a kink at the "reference point" that defines what is considered to be a loss and what is considered to be a gain. In the case at hand, it seems natural to assume that the "reference point" corresponds to consumption at the suggested retail price. Therefore, Tversky and Kahneman's theory applied 
to our present context suggests that the demand function $D\left(p_{r}, p_{s}\right)$ has a kink at $p_{r}=p_{s}$, i.e. that the marginal willingness to pay suddenly jumps downward once the price increases beyond the suggested retail price. The following figure shows the typical shape of a demand function $D$ satisfying conditions (4) and (5), thus displaying loss aversion in the sense of Tversky and Kahneman (1991).

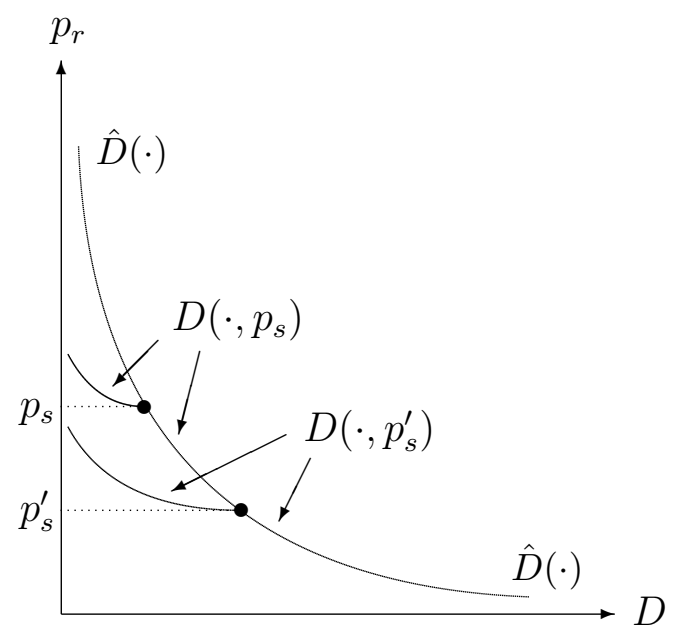

Figure 1: A typical demand function displaying loss aversion

It should be noted that Tversky and Kahneman's theory of loss aversion is a theory of individual preference and choice, not of demand as such. There are two alternative ways to derive a demand function with the postulated properties from individual preferences. First, one may view the market demand as resulting from the aggregation of the individual demand functions for a homogeneous good. Due to the sudden change of the marginal rate of substitution, loss aversion would induce a kink of the individual demand functions at the suggested retail price; since the kink thus occurs for all consumers at the same publicly announced price, the qualitative structure of the aggregate demand function is similar to that of the individual demand functions.

Secondly, one may view the demand function as resulting from the aggregation of the binary purchasing decision to buy or not to buy one unit of a discrete good in a large population with heterogeneous tastes. This is the approach taken in Rosenkranz (2003) who explicitly derives 
the kinked demand function in the case of a simple linear utility function. In contrast to the present analysis, Rosenkranz (2003) assumes that consumers experience an additional utility from purchasing the good at a lower than suggested price. In order to be able to compare the results to the case without price suggestion, we neglect this effect here. Note that this is in fact without loss of generality for any fixed $p_{s}$. On the other hand, neglecting the utility gain from purchasing the good at a lower price does restrict the way in which the demand function changes when $p_{s}$ varies (e.g. through condition (4) above).

\subsection{The Retailer's Problem}

By backwards induction, we first have to look at the retailer's problem which is now given by

$$
\max _{p_{r}}\left(p_{r}-p_{w}\right) \cdot D\left(p_{r}, p_{s}\right) .
$$

For all $p_{w}$ and $p_{s}$, denote by $p_{r}^{*}\left(p_{w}, p_{s}\right)$ the solution to this problem. In order to describe the qualitative behavior of the solution more specifically, we will make the following assumptions.

Assumption A The profit function $\left(p_{r}-p_{w}\right) \cdot \hat{D}\left(p_{r}\right)$ in (1) is twice continuously differentiable and, for any fixed $p_{w}$, strictly concave in $p_{r}$.

Assumption A implies that the solution $p_{r}^{m}$ in (2) is uniquely determined and characterized by the first order condition. Moreover, it guarantees that the solution $p_{r}^{m}\left(p_{w}\right)$ is a strictly increasing function of $p_{w}$ (see Lemma 2 in the appendix). In addition to Assumption A, we will use the following assumption.

Assumption B A monopolist can make positive profits on the market no matter how high marginal costs are, i.e. $p^{m}=p_{r}^{m}(c)>c$ for all $c>0$.

Assumptions $\mathrm{A}$ and $\mathrm{B}$ hold for a large class of demand functions; for instance, they are satisfied if $D$ has constant elasticity. ${ }^{8}$

The following result shows that, if the function $D\left(\cdot, p_{s}\right)$ has a strong enough kink at $p_{r}=p_{s}$, then the optimal retail price may stay at $p_{r}^{*}=p_{s}$ for a whole range of manufacturer price policies $p_{w}$. For all $p_{s}$, denote by $\underline{p_{w}}\left(p_{s}\right)$ the (unique) price satisfying

$$
p_{r}^{m}\left(\underline{p_{w}}\right)=p_{s} .
$$

\footnotetext{
${ }^{8}$ Requiring positive profits for all $c>0$ as in Assumption B is in fact not necessary for our results; it is postulated here in order to simplify the exposition.
} 
Moreover, denote by $\overline{p_{w}}\left(p_{s}\right)$ the largest wholesale price for which it is optimal for the retailer to set the retail price not higher than $p_{s}$, i.e.

$$
\overline{p_{w}}\left(p_{s}\right):=\max \left\{p_{w}: p_{r}^{*}\left(p_{w}, p_{s}\right) \leq p_{s}\right\} .
$$

While the values of $p_{w}$ and $\overline{p_{w}}$ in general depend on $p_{s}$, we omit this dependence for notational convenience whenever no confusion can arise.

Proposition 1 Suppose that Assumptions $A$ and $B$ hold, and consider a fixed $p_{s}$. Let $b>0$ be such that the slope $\partial D\left(\cdot, p_{s}\right) / \partial p_{w}$ of the demand function $D\left(\cdot, p_{s}\right)$ is bounded above by $-b$ for all $p_{r}>p_{s}$. If $b$ is sufficiently large, then $\overline{p_{w}}>\underline{p_{w}}$ and

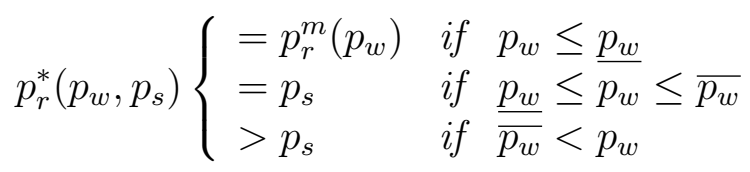

The result thus shows that the manufacturer, by choosing a price $p_{w}$ in the interval $\left[p_{w}, \overline{p_{w}}\right]$, can induce the retailer to set the price equal to the suggested retail price. Moreover, the optimal price set by the retailer is insensitive to changes of $p_{w}$ in that interval. This feature will be crucial in our characterization of equilibrium below. The length of the interval $\left[p_{w}, \overline{p_{w}}\right]$, in particular the magnitude of $\overline{p_{w}}$, depends on the extent of loss aversion, i.e. on the shape of the demand function for $p_{r}>p_{s}$. What is important for our purpose is that the interval $\left[\underline{p_{w}}, \overline{p_{w}}\right]$ has positive length whenever loss aversion is sufficiently strong.

The following figure summarizes the qualitative behavior of $p_{r}^{*}\left(\cdot, p_{s}\right)$.

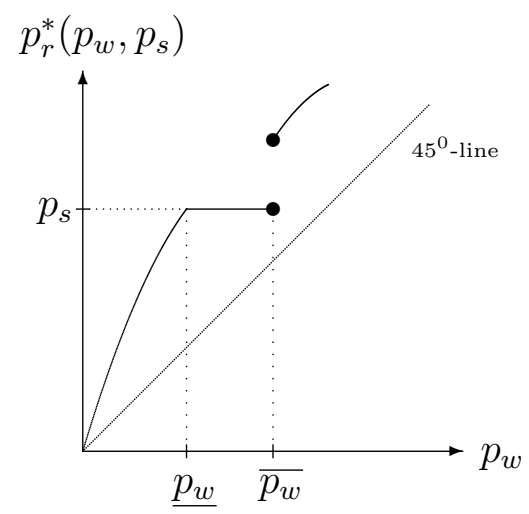

Figure 2: The retailer's optimal response to $p_{w}$ (for fixed $p_{s}$ ) 
Note that while there are two profit maximizing retail prices at $\overline{p_{w}}$, one at $p_{s}$ and one higher price with strictly lower demand, the retailer must choose $p_{s}$ as the response to $\overline{p_{w}}$ in equilibrium; indeed, otherwise the manufacturer would lower $p_{w}$ slightly in order to induce a strictly larger demand.

\subsection{The Manufacturer's Problem}

Consider now the manufacturer's problem

$$
\max _{p_{w}, p_{s}}\left(p_{w}-c\right) \cdot D\left(p_{r}^{*}\left(p_{w}, p_{s}\right), p_{s}\right)
$$

for $c>0$. The following result shows that the retailer never sets a price smaller than the suggested retail price in equilibrium.

Proposition 2 In the subgame perfect equilibrium of the price setting game, one has $p_{r}^{*}\left(p_{w}, p_{s}\right) \geq p_{s}$ under loss aversion.

To prove this, suppose by way of contradiction that $\left(p_{w}, p_{s}\right)$ is such that $p_{r}^{*}\left(p_{w}, p_{s}\right)<p_{s}$. By Proposition 1, one then obtains $p_{r}^{*}\left(p_{w}, p_{s}\right)=p_{r}^{m}\left(p_{w}\right)$. Since, by Assumption $\mathrm{B}, p_{w}<p_{r}^{m}\left(p_{w}\right)$, the manufacturer can thus raise profits by lowering the suggested retail price to $p_{s}^{\prime}:=p_{r}^{m}\left(p_{w}\right)$ and raising $p_{w}$ at the same time to $p_{w}^{\prime}:=\overline{p_{w}}\left(p_{s}^{\prime}\right)>p_{s}^{\prime}$. As already noted above, the retailer must choose $p_{r}=p_{s}^{\prime}$ as the response to $p_{w}^{\prime}=\overline{p_{w}}\left(p_{s}^{\prime}\right)$ in equilibrium. ${ }^{9}$

The argument just given also shows that the manufacturer always benefits from the additional possibility to announce a suggested retail price. Indeed, if $\left(p_{r}^{m}\left(p_{w}^{0}\right), p_{w}^{0}\right)$ is the equilibrium under double marginalization, the manufacturer can raise profits by setting the suggested retail price at $p_{s}^{0}:=p_{r}^{m}\left(p_{w}^{0}\right)$ and raising $p_{w}$ to the value $\overline{p_{w}}\left(p_{s}^{0}\right)$. We thus obtain the following result.

Proposition 3 Under loss aversion, the manufacturer is strictly better off in equilibrium than in the reference model without suggested retail price.

It is easily seen that, for any sufficiently large price suggestion $p_{s}$, the manufacturer can force the retailer to set the retail price $p_{r}$ exactly at the

\footnotetext{
${ }^{9}$ Casual observation suggests that retailers often undercut suggested retail prices and even advertise with that information. While this may appear to be in conflict with the assertion of Proposition 2, it arguably only shows that the suggested price was not set at the optimal level by the manufacturer in these cases. On the other hand, undercutting the price suggestion might occur in equilibrium if consumers derive additional utility from purchasing the good at a lower than suggested price, see Rosenkranz (2003).
} 
suggested level simply by choosing an appropriate wholesale price $p_{w} \cdot{ }^{10}$ However, this might in general not be optimal for the manufacturer. The reason is that the "degree of loss aversion" may vary unsystematically with the level of the suggested retail price. Since we have made no assumption in this respect so far, it is possible that the loss of demand due to a retail price strictly higher than the suggested price might be compensated for by the manufacturer's possibility to set a high wholesale price in equilibrium. The following result gives a simple sufficient condition on the demand function such that the retailer will always comply with the price suggestion in equilibrium.

For each fixed $p_{s}$, denote by $P_{r}\left(\cdot, p_{s}\right)$ the inverse demand function, i.e. $P_{r}\left(y, p_{s}\right)$ is the maximal retail price at which the quantity $y$ can be sold given that $p_{s}$ is the manufacturer's announced price suggestion. ${ }^{11}$

Proposition 4 Suppose that, for all $p_{s}>p_{s}^{\prime}$,

$$
y \cdot\left[P_{r}\left(y, p_{s}\right)-P_{r}\left(y, p_{s}^{\prime}\right)\right]
$$

is an increasing function of $y$ in the interval $\left[0, D\left(p_{s}, p_{s}\right)\right]$. Then, in equilibrium $p_{r}^{*}\left(p_{w}, p_{s}\right)=p_{s}$.

Note that the condition in Proposition 4 restricts the shape of the demand function only in the region where loss aversion is effective, i.e. where demand is strictly lower than it would be without suggested retail price. Roughly, it states that demand reacts more strongly to changes of the actual retail price than to changes of the suggested retail price. The condition thus corresponds to a restriction on the cross-price elasticity of demand with respect to $p_{r}$ and $p_{s}$. The idea behind the proof of Proposition 4 is as follows. Under the stated condition on the cross-price elasticity, the profit function of the retailer is a supermodular function of $y$ and $p_{s}$ in the relevant range. By a fundamental comparative statics result (see Milgrom and Shannon (1994) and Topkis (1998)), this implies that, for fixed $p_{w}$, the optimal quantity choice of the retailer is an increasing function of $p_{s}$ whenever loss aversion is effective. This, in turn, induces the manufacturer to choose $p_{w}$ and $p_{s}$ such that loss aversion will not be effective in equilibrium. Indeed, otherwise the manufacturer could raise profits by increasing $p_{s}$ since the retailer's response to this would involve a larger quantity choice (see the appendix for the complete argument).

\footnotetext{
${ }^{10}$ This can be verified as follows. Take any $p_{s} \geq p_{r}^{m}(0)$; since $p_{r}^{m}(\cdot)$ is strictly increasing, there exists $p_{w}$ such that $p_{r}^{m}\left(p_{w}\right)=p_{s}$. Thus, by Proposition $1, p_{r}^{*}\left(p_{w}, p_{s}\right)=$ $p_{s}$.

${ }^{11}$ Of course, we are assuming that, for any $p_{s}$, the demand function $D\left(\cdot, p_{s}\right)$ is strictly decreasing.
} 


\subsection{An Example}

In this final subsection, we provide a simple example of a demand function satisfying all postulated properties, including the condition on the crossprice elasticity in Proposition 4, and we compute the equilibrium for this function.

Specifically, suppose that the underlying demand function $\hat{D}$ has constant elasticity, say $\hat{\varepsilon}=-2$, so that $\hat{D}(p)=1 / p^{2}$, and by consequence, $p_{r}^{m}(c)=2 c$ for all $c$. Moreover, assume that whenever loss aversion becomes effective, i.e. whenever $p_{r}>p_{s}$, demand is linear with a uniform slope of $-1 / \beta$, as shown in Figure $3 .^{12}$

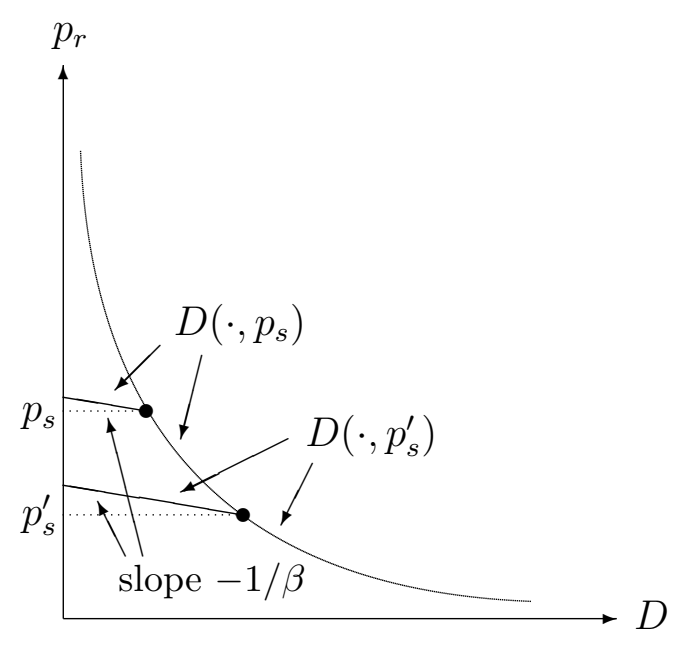

Figure 3: An example with "uniformly linear" loss aversion

Since, by construction, the difference between the inverse demand functions $P_{r}\left(\cdot, p_{s}\right)$ and $P_{r}\left(\cdot, p_{s}^{\prime}\right)$ is constant in the interval $\left[0, D\left(p_{s}, p_{s}\right)\right]$ when $p_{s}>p_{s}^{\prime}$, the example clearly satisfies the sufficient condition in Proposition 4 . We thus obtain $p^{*}\left(p_{w}, p_{s}\right)=p_{s}$ in equilibrium. This implies that, in equilibrium, the manufacturer chooses $p_{w}=\overline{p_{w}}\left(p_{s}\right)$, i.e. the highest wholesale price for which the retailer's best response is to set $p_{r}=p_{s}$ as in Section 3.2 above. Using the fact that demand is linear with slope $-1 / \beta$

\footnotetext{
${ }^{12}$ Thus, $-\beta$ is the slope of the inverse demand function. Note that, since Figure 3 depicts the inverse demand function, small values of $\beta$ correspond to "flat" slopes and thus to high loss aversion.
} 
whenever loss aversion is effective, one easily verifies that

$$
\overline{p_{w}}\left(p_{s}\right)=p_{s}-\frac{\beta}{\left(p_{s}\right)^{2}} .
$$

The manufacturer's profit, expressed as a function of $p_{s}$, is thus given by

$$
\left(p_{s}-\frac{\beta}{\left(p_{s}\right)^{2}}-c\right) \cdot \frac{1}{\left(p_{s}\right)^{2}}
$$

Maximization of (7), using the first-order condition, leads to the following cubic equation for the optimum

$$
\left(p_{s}\right)^{3}-2 c\left(p_{s}\right)^{2}-4 \beta=0,
$$

which has the following unique solution in the reals,

$$
\begin{aligned}
p_{s}=\frac{1}{3}\left(2 c+\frac{2 \cdot 4^{1 / 3} c^{2}}{\left(27 \beta+4 c^{3}+\right.}\right. & \left.3 \sqrt{\left.3 \beta\left(27 \beta+8 c^{3}\right)\right)^{1 / 3}}\right)+ \\
+ & \frac{1}{3}\left(54 \beta+8 c^{3}+6 \sqrt{3 \beta\left(27 \beta+8 c^{3}\right)}\right)^{1 / 3}
\end{aligned}
$$

It can be shown that the solution $p_{s}$ is increasing in $\beta$. Moreover, it is easily verified that for $\beta \rightarrow 0$, one obtains $p_{s}=2 c$. In other words, if loss aversion is extreme in the sense that demand becomes zero once the retail price exceeds the suggested retail price, then the manufacturer can realize the monopoly profit on the market by setting both $p_{w}$ and $p_{s}$ at the monopoly price level. The retailer must comply with the price suggestion in equilibrium, setting the retail price at the monopoly price level as well. Note that while the retailer thus makes zero profits and is therefore indifferent to leaving the market, he/she must stay in the market in equilibrium since otherwise the manufacturer would lower $p_{w}$ slightly below the suggested retail price. ${ }^{13}$

Note that since the optimal value of $p_{s}$ given by equation (9) is a continuous and increasing function of $\beta$, the equilibrium values of $p_{r}$ and $p_{s}$ are strictly lower than the retail price in the reference model under double marginalization provided that loss aversion is sufficiently strong. Indeed, under double marginalization the optimal retail price is $p_{r}^{m}(2 c)=4 c$, while

\footnotetext{
${ }^{13}$ We are assuming here that the manufacturer has no possibility to sell directly to consumers in the short-run, so that he/she makes zero profits once the retailer has left the market.
} 
$p_{r}$ and $p_{s}$ are equal and close to $2 c$ if $\beta$ is small. The positive welfare effect due to the lower retail price is however offset by the loss in consumer surplus due to loss aversion. The overall welfare effect of price suggestions is thus ambiguous.

\section{Conclusion}

Our analysis has shown that a non-binding suggested retail price can be explained as a strategic device to increase manufacturer's profits in a simple model of two vertically related monopoly markets. According to the "reference-dependent" theory of consumer choice, we assumed that a suggested retail price serves as a reference point and that consumers are loss averse. Our main finding is that the manufacturer always benefits from a publicly announced price suggestion and would thus always invest into a retail price suggesting advertisement. Indeed, if loss aversion is sufficiently strong, the retailer sets a price at least as high as the suggested price in equilibrium, and profits are shifted from the retailer to the manufacturer. Under a simple condition on the cross-price elasticity with respect to the actual and the suggested retail price, the retailer in fact complies with the price suggestion in equilibrium. If loss aversion becomes extreme, the manufacturer can realize the monopoly profit on the market by setting both the wholesale price and the suggested retail price at the monopoly price level. 


\section{Appendix: Remaining Proofs}

Lemma 2 Suppose that the retailer's profit function

$$
\Pi\left(p_{r}, p_{w}\right):=\left(p_{r}-p_{w}\right) \cdot \hat{D}\left(p_{r}\right)
$$

is twice continuously differentiable and, for any fixed $p_{w}$, strictly concave in $p_{r}$ (Assumption A). Then, the optimal retail price $p_{r}^{m}\left(p_{w}\right)$ is uniquely determined and strictly monotone in $p_{w}$.

Proof of Lemma 2 Clearly, under strict concavity, the solution is characterized by the first order condition, i.e. the solution $p_{r}^{m}\left(p_{w}\right)$ satisfies

$$
\frac{\partial \Pi}{\partial p_{r}}\left(p_{r}^{m}\left(p_{w}\right), p_{w}\right)=0 .
$$

By the implicit function theorem, we have

$$
\frac{d p_{r}^{m}}{d p_{w}}=\frac{-\partial^{2} \Pi / \partial p_{r} \partial p_{w}}{\partial^{2} \Pi / \partial p_{r}^{2}}
$$

The nominator of the right-hand-side in (10) is negative since the demand function is downward sloping, and the denominator is negative due to the concavity assumption. Thus, the sign of $d p_{r}^{m} / d p_{w}$ is positive, i.e. $p_{r}^{m}(\cdot)$ is strictly increasing.

Proof of Proposition 1 First, we show that for $p_{w} \leq p_{w}\left(p_{s}\right)$ the optimal retail price is given by $p_{r}^{m}\left(p_{w}\right)$. Thus, fix $p_{w}$ and $p_{s}$ such that $p_{w} \leq \underline{p_{w}}\left(p_{s}\right)$. One has, for all $p_{r}$,

$$
\begin{aligned}
\left(p_{r}^{m}\left(p_{w}\right)-p_{w}\right) \cdot D\left(p_{r}^{m}\left(p_{w}\right), p_{s}\right) & =\left(p_{r}^{m}\left(p_{w}\right)-p_{w}\right) \cdot \hat{D}\left(p_{r}^{m}\left(p_{w}\right)\right) \\
& \geq\left(p_{r}-p_{w}\right) \cdot \hat{D}\left(p_{r}\right) \\
& \geq\left(p_{r}-p_{w}\right) \cdot D\left(p_{r}, p_{s}\right)
\end{aligned}
$$

The equality (11) follows from assumption (4) and the fact that $p_{r}^{m}\left(p_{w}\right) \leq$ $p_{s}$ due to $p_{w} \leq \underline{p_{w}}\left(p_{s}\right)$ and the monotonicity of $p_{r}^{m}(\cdot)$. The inequality in (12) follows from optimality of $p_{r}^{m}$, and (13) follows from assumptions (4) and (5). This shows that $p_{r}^{m}\left(p_{w}\right)$ is indeed the optimal retail price whenever $p_{w} \leq \underline{p_{w}}\left(p_{s}\right)$.

Consider now fixed $p_{w}$ and $p_{s}$ such that $p_{w}<p_{w}<p_{s}$, and suppose that the slope $\frac{\partial D\left(\cdot, p_{s}\right)}{\partial p_{w}}$ of the demand function $D\left(\cdot, p_{s}\right)$ is bounded above 
by $-b$. Consider $\epsilon>0$, and suppose that the retailer sets a price $p_{s}+\epsilon$. For the corresponding profit one obtains

$$
\begin{aligned}
& \left(p_{s}+\epsilon-p_{w}\right) \cdot D\left(p_{s}+\epsilon, p_{s}\right) \\
& \quad \leq\left(p_{s}+\epsilon-p_{w}\right) \cdot\left[D\left(p_{s}, p_{s}\right)-b \cdot \epsilon\right] \\
& \quad=\left(p_{s}-p_{w}\right) \cdot D\left(p_{s}, p_{s}\right)-\left(p_{s}-p_{w}\right) \cdot b \cdot \epsilon+\epsilon \cdot \hat{D}\left(p_{s}\right)-b \cdot \epsilon^{2} \\
& \quad=\Pi\left(p_{s}, p_{w}\right)+\epsilon \cdot \hat{D}\left(p_{s}\right)-b \cdot\left[\left(p_{s}-p_{w}\right) \cdot \epsilon+\epsilon^{2}\right]
\end{aligned}
$$

This shows that, for any positive $\epsilon$, the retailer's profit at $p_{r}=p_{s}+\epsilon$ is smaller than his/her profit $\Pi\left(p_{s}, p_{w}\right)$ at $p_{r}=p_{s}$ if $b$ is large enough. Since the profit function $\Pi\left(\cdot, p_{w}\right)$ is concave and since $p_{r}^{m}\left(p_{w}\right) \geq p_{s}, \Pi\left(p_{s}, p_{w}\right)$ is also greater than $\Pi\left(p_{r}, p_{w}\right)$ for all $p_{r}<p_{s}$. Thus, if $p_{w}<p_{w}<p_{s}$, the optimal retail price is indeed $p_{s}$ provided that $b$ is sufficiently large, i.e. provided that the loss aversion is sufficiently strong.

Proof of Propositions $2 \& 3$ in text.

Proof of Proposition 4 The stated condition asserts that, for any fixed $p_{w}$, the retailer's profit function

$$
\Pi\left(y, p_{s}\right):=y \cdot P_{r}\left(y, p_{s}\right)-y \cdot p_{w}
$$

is a supermodular function of the quantity $y$ and the suggested price $p_{s}$ in the interval $\left[0, D\left(p_{s}, p_{s}\right)\right]$. By Theorem 2.8.2 in Topkis (1998), this implies that whenever the retailer's optimal quantity lies in the interval $\left[0, D\left(p_{s}, p_{s}\right)\right]$, it is an increasing function of $p_{s}$.

In order to prove the assertion of the proposition, assume by contradiction that $p_{r}^{*}\left(\tilde{p}_{w}, \tilde{p}_{s}\right)>\tilde{p}_{s}$ in equilibrium, i.e. that the retailer's optimal quantity is in the interval $\left[0, D\left(\tilde{p}_{s}, \tilde{p}_{s}\right)\right]$. By assumption, it is then an increasing function of $p_{s}$ so that raising the price suggestion will never decrease the manufacturer's profit. But in this case, the manufacturer can realize a strictly higher profit by raising $p_{s}$ until $p_{r}^{*}\left(\tilde{p}_{w}, p_{s}\right)=p_{s}$ and then raising $p_{w}$ a little bit according to Proposition 1 . 


\section{References}

[1] Bernheim B. D. and M. D. Whinston (1985), Common Marketing Agency as a Device for Facilitating Collusion, RAND Journal of Economics 16 (2), 269-281.

[2] Jullien, B. and P. Rey (2000), Resale Price Maintenance and Collusion, CEPR Discussion Paper No. 2553.

[3] Kahneman, D. (1992), Reference Points, Anchors, Norms, and Mixed Feelings, Organizational Behavior and Human Decision Processes 51, 296-312.

[4] Kahneman, D., Knetsch, J. and R. Thaler (1991), The Endowment Effect, Loss Aversion, and Status Quo Bias, Journal of Economic Perspectives 5, 193-206.

[5] Kahneman, D. and A. Tversky (1979), Prospect Theory: An Analysis of Decisions under Risk, Econometrica 47, 263-291.

[6] Kahneman, D. and A. Tversky (1984), Choices, Values and Frames, American Psychologist, XXXIX, 341-50.

[7] Matthewson, F. and R. Winter (1998), The Law and Economics of Resale Price Maintenance, Review of Industrial Organization 13 (1), $57-84$.

[8] Milgrom, P. and C. Shannon (1994), Monotone Comparative Statics, Econometrica 62, 157-180.

[9] OCDE (1997), Resale Price Maintenance, Competition Policy Roundtables, OCDE/GD(97)229 (1997).

[10] Rosenkranz, S. (2003), The Manufacturer's Suggested Retail Price, Utrecht School of Economics, T.C. Koopmans Research Institute, Discussion Paper Series 03-05.

[11] Spengler, J. J. (1950), Vertical Integration and Antitrust Policy, Journal of Political Economy 58 (4), 347-352.

[12] Topkis, D. (1998), Supermodularity and Complementarity, Princeton University Press, Princeton. 
[13] Tversky, A. and D. Kahneman (1991), Loss Aversion in Riskless Choices: A Reference-Dependent Model, Quarterly Journal of Economics, 1039-1061. 